\title{
Momento de transição
}

Em maio último, durante o XIII Congresso Brasileiro de Medicina do Esporte, tive a honra de ter sido convidado para fazer parte da chapa que foi eleita para a diretoria da Sociedade Brasileira de Medicina do Esporte (SBME). Dessa forma, deverei ocupar o cargo de Editor da Revista Brasileira de Medicina do Esporte nos próximos dois anos.

É inegável o valor do trabalho realizado pelo Editor que me precedeu, o Dr. João Gilberto Carazzato, que foi um dos responsáveis pela deflagração do processo que originou esta revista.

Entretanto, acreditamos na idéia de que mesmo o que já é de boa qualidade pode se tornar ainda melhor e, dessa forma, pretendemos realizar algumas modificações na Revista, tarefa para a qual contaremos com a colaboração mais direta dos colegas que compõem o Conselho Editorial e a diretoria da SBME. Obviamente, estamos à disposição de colegas de todo o Brasil e de outros países, que queiram colaborar.

Queremos deixar claro que não pretendemos mudar somente "por mudar" ou só para deixar a "nossa marca". Desde a nossa eleição, conversamos com colegas da especialidade de todo o país e nos pareceu evidente que as alterações que pretendemos realizar são consensuais e representam uma evolução natural da nossa Revista. Elas serão observadas aos poucos, neste e nos próximos números.

Uma das nossas prioridades é regularizar a periodicidade da revista. Isto é fundamental para assegurar a credibilidade da Revista do ponto de vista científico e inclusive do ponto de vista comercial, junto às empresas que ajudam a financiá-la.

Sabemos que a literatura existente em língua portuguesa nas áreas de Medicina do Exercício e do Esporte e Ciências do Esporte é relativamente escassa, limitando muito a possibilidade de atualização de colegas que não dominam outros idiomas. Assim, consideramos que a Revista Brasileira de Medicina do Esporte possui um papel fundamentalmente educativo, no sentido de tornar disponível informações científicas de boa qualidade, em língua portuguesa. No nosso julgamento, este aspecto educativo é tão importante quanto o óbvio papel científico da Revista, que naturalmente também será enfatizado.

Temos no Brasil inteiro Sociedades de Medicina do Esporte estaduais, muitas funcionando satisfatoriamente, algumas extremamente atuantes e outras em processo de reestruturação. Acreditamos que uma organização será mais consistente em nível nacional se as suas congêneres regionais forem também fortes. Como órgão oficial da SBME, a Revista Brasileira de Medicina do Esporte não poderia deixar de desempenhar seu papel, colaborando com o processo de fortalecimento das sociedades regionais. Dessa forma, a partir do próximo número estaremos colocando uma página à disposição das presidências das sociedades regionais de Medicina do Esporte para que divulguem suas atividades, espaço este que poderá ser ampliado de acordo com a demanda.

Neste número temos uma modificação bastante visível: a capa, mais sóbria, e na opinião da maioria dos colegas, mais adequada para este novo momento da Revista. Modificamos ainda as instruções aos autores e, dando início à informatização da Revista, introduzimos um endereço de $e$-mail (correio eletrônico), para que possamos estabelecer uma comunicação rápida, eficiente e com baixo custo. Mensagens ao Editor, ao Conselho Editorial, sugestões e inclusive artigos (vide Instruções para Autores) podem ser enviados por esta via. O endereço é: rbme@mtec.com.br.

Este número está sendo publicado no momento de transição entre duas diretorias da Sociedade Brasileira de Medicina do Esporte. Sai a diretoria que teve como presidente o Dr. João Ricardo 
Turra Magni, que sem dúvida realizou um belo trabalho; e entra a nova diretoria, cujo presidente é o Dr. Marcelo Salazar de Veiga Pessoa. Aproveitando então este momento de mudança do comando da Medicina do Esporte no Brasil, julgamos oportuno trazer neste número algumas mensagens, de colegas que ocupam posições-chave na Medicina do Esporte em nível nacional e mundial:

- Mensagem do Presidente da FIMS (Fédération Internationale de Médecine Sportive), Prof. Dr. Eduardo Henrique De Rose;

- Mensagem do Presidente da COPAMEDE (Confederación Panamericana de Medicina del Deporte), Dr. Carlos Pablo D’Angelo;

- Mensagem do último Ex-Presidente da SBME (Sociedade Brasileira de Medicina do Esporte), Dr. João Ricardo Turra Magni;

- Mensagem do atual Presidente da SBME, Dr. Marcelo Salazar de Veiga Pessoa, empossado durante o XIII Congresso Brasileiro de Medicina do Esporte;

- Mensagem do Presidente-Eleito, Dr. Marcos Aurélio Brazão de Oliveira, eleito também no último Congresso, devendo assumir em 1999.

Desde a nossa eleição, no início de maio, trabalhamos rápido e já conseguimos trazer documentos de reconhecida importância internacional, para publicação na nossa Revista. Conseguimos permissão para tradução para a língua portuguesa e publicação na Revista Brasileira de Medicina do Esporte dos Posicionamentos Oficiais da FIMS e do American College of Sports Medicine (ACSM). Passaremos então a publicar um documento da FIMS e do ACSM por número.

Ainda neste número, registrando o alto nível científico dos eventos, trazemos os resumos dos temas-livres aceitos para apresentação no XIII Congresso Brasileiro e XVII Congresso PanAmericano de Medicina do Esporte, realizados em Gramado-RS, entre 7 e 10 de maio último.

A seção Calendário continua, divulgando eventos científicos nas áreas de Medicina do Exercício e do Esporte e Ciências do Esporte.

Finalmente, apesar de ser o óbvio, gostaria de reiterar que, sendo a Revista Brasileira de Medicina do Esporte o órgão oficial da Sociedade Brasileira de Medicina do Esporte, ela estará à disposição de todos os colegas da área de saúde que atuam nas áreas de Medicina do Exercício e do Esporte e Ciências do Esporte.

José Kawazoe Lazzoli

Editor Científico 